\title{
Managing the maintenance inventory of a cement manufacturer
}

\begin{abstract}
Authors:
Morné Eloff ${ }^{1}$

Stephen Carstens ${ }^{2}$

Affiliations:

${ }^{1}$ Department of Business

Management, University of

Johannesburg, South Africa

${ }^{2}$ Institute of Transport and Logistics Studies (Africa), University of Johannesburg, South Africa
\end{abstract}

\section{Correspondence to:}

Stephen Carstens

Email:

stephcar@global.co.za

Postal address:

PO Box 84366, Greenside

3034, South Africa

Dates:

Received: 19 June 2013

Accepted: 03 Oct. 2013

Published: 20 Nov. 2013

How to cite this article:

Eloff, M. \& Carstens, S., 2013,

'Managing the maintenance

inventory of a cement

manufacturer', Journal of

Transport and Supply Chain

Management 7(1), Art.

\#104, 7 pages. http://dx.doi.

org/10.4102/jtscm.v7i1.104

\section{Copyright:}

(C) 2013. The Authors.

Licensee: AOSIS

OpenJournals. This work

is licensed under the

Creative Commons

Attribution License.

Read online:
Inventory management is a crucial aspect of managing a company successfully. This is even more apparent in the case of maintenance inventories for production equipment, which impact directly on production equipment efficiency. This is a typical inventory management issue for a cement manufacturer that faces the problem of managing its maintenance inventories optimally when certain maintenance items have exceptionally long lead times (100 weeks) and values in excess of R500 000. An assessment of the cement manufacturer's approach to managing its maintenance inventories indicated various shortcomings, which have resulted in a significant level of obsolescence. One approach to managing maintenance inventories efficiently is to implement a classification of the inventory items in terms of their criticality to the cement production process. The critical nature of a component could be established through a risk-based approach (minimisation of the risk of production loss) and taking into account the type of maintenance (planned vs unplanned) that the component is required for. A risk-based approach should form the basis of the maintenance inventory management of the cement manufacturer as this would allow the cement manufacturer to utilise other inventory management methods effectively. In addition, it is important to ensure that employees are well versed in the different inventory management approaches utilised and that high levels of integration between departments are pursued.

\section{Introduction}

The existence of inventory in any supply chain is associated with high risk and high impact (Bowersox, Closs \& Cooper 2002). Inventory shortages (stockouts) may result in customer dissatisfaction and/or the disruption of manufacturing or marketing plans. However, too much inventory increases costs and reduces profitability (Bowersox et al. 2002). Therefore, inventory management, which includes addressing the functionality, the principles, the cost and impact associated with carrying the inventory, plays an important role in the success of any company (Bowersox et al. 2002).

Inventory carrying cost relates to the cost of maintaining the inventory and may constitute a significant percentage of total product value and it could also have an effect on the profitability of the organisation (Lambert, Stock, \& Elram 2008). Karrlson, Morichetto and Schwerin (2007) showed that the investment in inventory in some companies could be more than $20 \%$ of the total assets. It is therefore important for a company to manage inventory levels and its associated costs optimally.

For a manufacturer, the financial and operational impacts become more pronounced if maintenance inventories are considered, as a stockout on a maintenance part may lead to production losses. Maintenance inventory refers to all the inventories of spare parts, components and so on that support the manufacturing process, but are not included in the final product.

The objective of this research was to evaluate the management of maintenance inventories at a South African cement manufacturer with operations in South Africa and its neighbouring countries: Botswana, Swaziland, Namibia and Lesotho. The company produces various types of cement at four cement plants in South Africa and a blending plant in Swaziland. Its maintenance inventories for the plant equipment are kept at five warehouses situated at these cement plants.

The optimal management of the maintenance inventories of the cement manufacturer is crucial to the financial success of the company. This is due to the high capital value of parts, the long lead times for supply and the major impact on the operation of the cement mills in the case of a component stockout.

Most of the data collected from the company is treated as confidential and only non-critical data is revealed in this study. A combined total number of 19000 maintenance items (spares or parts) 
are kept in inventory valued at R143 million (2011 Rand value). The 30 most expensive maintenance inventory items at the cement manufacturer's five warehousing stores are all valued in excess of R500 000, with the most expensive part valued at $\mathrm{R} 3.3 \mathrm{~m}$.

Apart from the high value of maintenance inventories, the cement manufacturer also faces the complication of long lead times for the supply of some of the parts since these have to be manufactured to order. For example, certain critical parts that are required in a vertical cement roller have lead times of approximately 100 weeks. Furthermore, the obsolescence cost may also be high since the part kept in stock may be written off due to its age if it is not required for maintenance. The cement manufacturer makes provision for obsolescence based on the movement (years in inventory) of maintenance inventory items or if the item is damaged in storage. Table 1 shows some examples of parts and their values (2011 Rand value), as well as the time in stock.

The cement manufacturer uses the following approach to calculate the level of obsolescence.

Review item by item and write the specific item off 100\% if:

- The related equipment is permanently out of use

- There is no related equipment

- The spare part is damaged.

The remaining spare part inventories have an allowance for obsolescence by applying the following rule:

- $30 \%$ provision for obsolescence after one year without usage

- $50 \%$ provision for obsolescence after two years without usage

- $80 \%$ provision for obsolescence after three years without usage.

This approach results in a provision for obsolescence amounting to R48.64 m (Table 2).

Note that insurance spares are maintenance spares that are separately indicated and classified in the management accounts. These are compulsory inventory items in the risk insurance policy of the cement manufacturer. The spares usually have a very slow turnover, but due to the risk to the business in terms of production and subsequent cement volumes and turnover, these spares form an integral part of

TABLE 1: Parts cost and movement history.

\begin{tabular}{lll}
\hline Part & Last movement date & Value (Rand) \\
\hline Raw mill table liner & October 2008 & R3 331 193 \\
Motor 1959 kW & April 2004 & R1 193314 \\
Spherical roller & July 2006 & R668 451 \\
Elevator chain & April 2011 & R654 354 \\
\hline
\end{tabular}

the maintenance inventory policy of the cement industry. Therefore, for the purposes of this research, these spares were excluded from the calculation of the obsolescence provision.

From Table 2, it follows that the maintenance inventories include parts that have had no movement in one or more years, which amount to R80.9 $\mathrm{m}$ and account for $57 \%$ of the total inventory value.

One of the main focus areas of the cement manufacturer is the impact of maintenance inventory stockouts on production. Therefore, the cement manufacturer uses operating equipment efficiencies (OOEs) as a key performance indicator (KPI). The world standard for OEEs of cement manufacturers of $85 \%$ can only be achieved through very good maintenance practices and programmes combined with exceptional maintenance inventory levels and good maintenance inventory strategies.

Although there are large volumes of academic research on maintenance inventory management, not many companies seem to implement these approaches to optimally manage their maintenance inventories (Cavalieri et al. 2008). This is also true for the cement manufacturer in this study that manages its maintenance inventories by using approaches such as strategic sourcing, supply contracts in association with vendor managed inventory (VMI) and the centralisation of certain inventory items. Most of the research includes some form of inventory classification, which is not a focus area of the cement manufacturer. Critical analysis and 'weighting' of inventory items (or groups of items) ensures that the importance of each item in maintaining production is reflected in its associated stock levels.

Bharadwaj, Silberschmidt and Wintle (2011) found that maintenance inventories are mainly influenced by the maintenance policies of the equipment. Scheduled maintenance has a relatively predictable demand for spares and it is possible to order parts to arrive just in time for use and indeed not stock parts at all. Unplanned maintenance as a result of breakdowns and the lack of available parts may result in production losses as well as the additional cost of procuring the parts at short notice.

\section{Research method and design}

This research aimed to assess the methods used by a cement manufacturer to manage its maintenance inventories. The research was based on a survey of a sample of the company's employees and focused on the respondents' understanding or knowledge of various aspects of managing its maintenance inventory.

TABLE 2: Calculation of obsolescence provision.

\begin{tabular}{|c|c|c|c|c|c|}
\hline Cost Item & Current $(0 \%)$ & One year $(30 \%)$ & Two years $(50 \%)$ & Three years and more $(80 \%)$ & Total \\
\hline Inventory value & R62 203508 & R16 128733 & R14 332537 & R50 443009 & R143 107787 \\
\hline Obsolescence & - & R4 838620 & R7 166268 & R40 354407 & R52 359295 \\
\hline Minus: Insurance spares & - & R177 169 & R586 421 & R2 955252 & R3 718842 \\
\hline Total & & & & & R48 640453 \\
\hline
\end{tabular}


The survey was aimed at the relevant employees (middle and senior level management) of the cement manufacturer and was based on a questionnaire that included questions relating to a combination of choices (selection from a list of alternatives), binary choices (yes or no) and ranking of alternatives. In addition, in separate interviews, the respondents were given the opportunity to provide additional information on relevant questions.

A total of 17 employees from the accounting, maintenance engineering and supply chain departments involved in inventory management were surveyed. Due to the small number of respondents the survey results are mainly descriptive of nature, but they provide a clear picture of the maintenance inventory management approach that is followed by the cement manufacturer and highlight the potential shortcomings of this approach.

\section{Literature review}

Holding inventory is associated with a number of high costs, therefore it is important to determine the carrying cost, as the value of the carrying cost may have a significant impact on the inventory management approach (Berling 2005), as well as on the profitability of the organisation (Lambert $e t$ al. 2008). The carrying cost of inventory consists of capital cost, storage cost and risk cost, each with a contribution relative to the value of the inventory (Hugo, Badenhorst-Weiss \& Van Rooyen 2002).

According to Karrlson et al. (2007), holding inventory is associated with four types of risk: risk of obsolescence; damage; pilferage; and relocation.

One of the highest inventory risk cost factors to the cement manufacturer is the risk of obsolescence, as certain spares are kept in stock to facilitate the maintenance function in the case of unplanned events such as equipment breakdowns. Obsolescence costs can be directly attributed to inventory that is slow moving, for example, spare parts not moving for up to three years, which can result in these parts becoming obsolete or damaged in the warehouse. An example of this type of spare part is a v-belt, which, due to age and incorrect storage, could become worn and unusable

The development of global sourcing strategies has become a key success factor and an increasingly attractive option for organisations to respond to competitive demand (Monczka Trent \& Handfield 2005). Excellent supply chain management requires suppliers and customers working together to ensure that overall supply chain objectives are met, which could be achieved through strategic sourcing (Langley et al. 2009). This approach allows a company to deal effectively with the sourcing of items with long lead times and associated supply uncertainty. However, supply uncertainty may be mitigated through value-creation initiatives such as logistical information exchange between supplier and customer, for example, the supplier's production process, delivery reliability, technical specifications, delivery schedules and so forth (Chen \& Paulray 2004).
The sourcing strategies of the cement manufacturer are built around the fundamentals of global sourcing. This is done in order to mitigate the impact of supply uncertainty as the quality and availability of suppliers for critical components are limited in the cement industry. Therefore, the cement manufacturer enters into long-term agreements with suppliers in order to ensure sustainability of supply, for example, vendor-managed inventory or consignment stock. Supplier performance is a key issue that has to be monitored closely in the event of the cement manufacturer entering into long-term agreements with certain suppliers.

An additional element of supply contracts is the improvement of performance through the implementation of approaches, such as vendor-managed inventory (VMI) and consignment inventory. This is in line with the findings of Liu and Cetinkaya (2005), who found that larger retailers may have a bigger influence over their suppliers as a result of their bargaining power. This approach has led to the formation of buyer-driven channels, where the power lies more with the buyer rather than the supplier; it could ensure the terms of purchase supersede the terms of supply.

In supply contract design the party holding the leadership usually realises the greater profits (Liu \& Cetinkaya 2005). In many instances, different cement manufacturers use the same supplier for their maintenance inventory, such as engineered items. One way of implementing a buyerdriven channel is through collaboration between different cement manufacturers and therefore dictating supply contract requirements. However, this type of arrangement may have a limited applicability since it requires competing manufacturers working together.

Supplier integration is another key principle in the supply chain management process that can add value to overall performance and efficiency of the supply chain, as well as the business operation as a whole (Monczka et al. 2005). Vendormanaged inventory (VMI) allows for the customer (buyer) to enter into formal agreements with their suppliers that offer on-site support, where the risk of carrying inventory is with the supplier. In the case of the cement manufacturer it is important to consider that many of the critical components are from single source suppliers and that it requires a great deal of trust to develop the required relationship. The cement manufacturer has implemented only certain aspects of supplier integration, such as consignment stock and VMI agreements, with a limited number of suppliers

Other inventory-reducing strategies considered by the cement manufacturer are the following.

\section{Centralisation of inventory}

Rather than having inventory warehouses at different locations, the level of safety stocks can be reduced by centralising inventory in a single warehouse (Landers et al. 2000). However, if supply is disrupted and demand is stochastic, then a decentralised inventory system is optimal (Schmitt, Snyder \& Shen 2008). 


\section{Virtual warehousing}

Virtual warehousing is based on the principle that all inventories across many locations are regarded as one common inventory pool (Landers et al. 2000). Such an approach may be associated with the transhipment of goods between warehouses at the same echelon level in the supply chain (Landers et al. 2000).

These methods of reducing inventory can only be implemented if the warehouse infrastructure and the transportation to the various cement locations are well managed and the supply of the spares is possible within a short space of time. However, the cement manufacturer keeps inventory at five locations that are widely geographically dispersed. From a virtual warehousing perspective, the widespread geographical locations result in increased lead times and transport costs that could exceed the initial savings of the inventory reduction. In addition, the risk of supply disruptions may have a significant impact on the operations of the cement manufacturer, rendering such an approach unsuitable. However, certain parts are stored at a central warehouse in South Africa and are available to any plant, based on stock reservations and orders.

The nature of maintenance inventories (long lead times, critical to production and more) necessitates a different approach, with a strong focus on the level of criticality of each part (or groups of parts) and the associated risk to the operation. It has become increasingly important to focus on advanced approaches to reflect the complexity and innovation required to optimise maintenance inventory (Bharadwaj et al. 2011). The objective of maintenance is to ensure that production can proceed continuously without delays. This implies that, in the case of machine breakdowns, maintenance should take into account the unpredictable nature of the demand for spares (Bošnjaković 2010).

Two main approaches have been proposed to deal with the unpredictable nature of the demand for spares: mathematical models and the multi-attribute classification of spares (Baluch et al. 2013). The mathematical models are based on linear, dynamic and goal programming, as well as simulation and they are, in general, very complex (Baluch et al. 2013).

The multi-attribute classification of maintenance spares takes into account attributes such as usage rates, lead time of supply and cost (Baluch et al. 2013). Bharadwaj et al. (2011) proposed a similar approach based on the risk profiles of the spares as well as the likelihood of a failure to meet the demand for a spare and the consequences should the parts not be available. The risk profile is then used to find an optimal level of inventory, such that financial benefit is maximised together with an acceptable risk level (Bharadwaj et al. 2011).

Subsequent to a risk classification of the maintenance spares, a just-in-time (JIT) approach could be utilised for certain spares. This requires manufacturers working together with their suppliers and transport providers to get the required items to assembly lines at the precise time required for production (Gourdin 2001). The JIT purchasing system can be implemented with success for scheduled maintenance, where operational downtime is planned and the maintenance engineers specify the spare part requirements for a specific date and time.

\section{Results}

The results of the survey highlighted the lack of knowledge about suitable maintenance inventory management approaches and integration between the relevant parties at the cement manufacturer. In order to implement an effective inventory management method, this needs to be addressed.

The length of service of the respondents ranged from one year to 40 years, with an average employment term of 13 years, as indicated by the frequency distribution in Figure 1.

The respondents were employed in the maintenance engineering, accounting and supply chain departments (Figure 2); approximately $47 \%$ of the respondents had a postgraduate education.

The respondents that indicated Management as their business area were involved in the general management of the plants. This indicates that the sample was representative of the

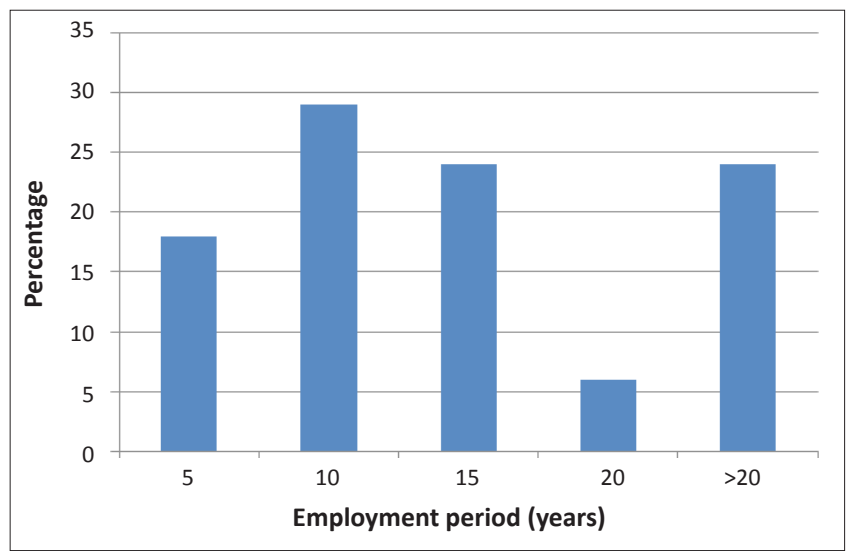

FIGURE 1: Employment period (years)

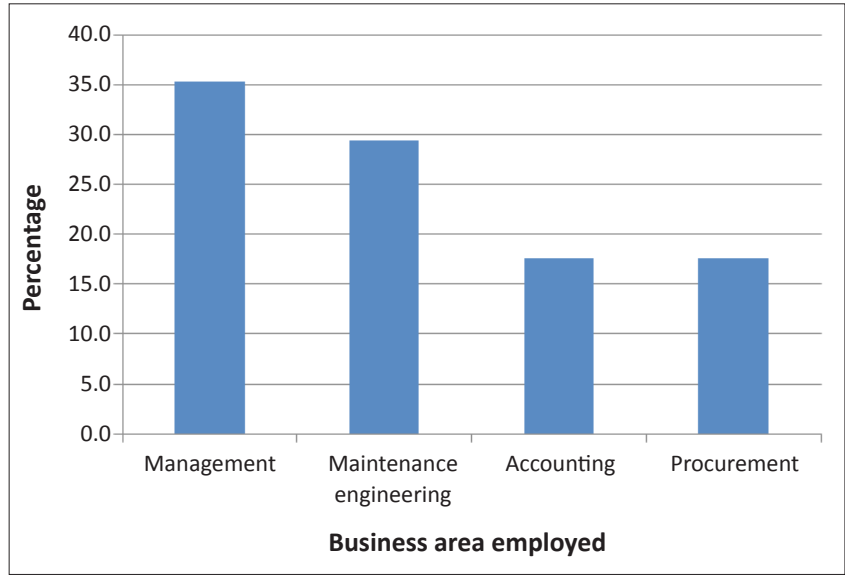

FIGURE 2: Business area of employment. 
business areas involved in maintenance inventories and that the respondents had ample experience with managing maintenance inventories at the cement manufacturer.

A large proportion of the respondents (65\%) was under the impression that inventory-carrying cost was calculated within the company; they were not aware of the actual cost of carrying the maintenance inventory. However, the carrying cost of the maintenance inventory was not calculated at the time of the survey.

A small proportion (18\%) of the respondents indicated that the manufacturer's maintenance inventory levels could be rated as poor, that is, not having sufficient stock (as indicated by Figure 3).

The majority of the respondents indicated that the inventory levels were satisfactory, which is not surprising given the fact that a large proportion (57\%) of the total inventory value could be attributed to spare items that had not moved in one or more years, resulting in an obsolescence provision of $34 \%$. Box 1 shows some of the reasons provided by the respondents for the positive ratings in Figure 3.

Although the average employment period of the respondents was 13 years, many of the respondents were not sure which material planning system and order planning system for maintenance items were used by the manufacturer. Only $53 \%$ of the respondents were correct in indicating that a material requirement planning (MRP) system in conjunction with an economic order quantity approach (EOQ) were used (Figure 4).

The majority of the respondents (95\%) agreed that maintenance inventory levels impact on the manufacturer's operating equipment efficiency (OEE), which is a very important key performance indicator of the efficiency of the production facilities. It was therefore not surprising that $47 \%$ of the respondents were of the opinion that non-critical maintenance items should be kept in stock.

Table 3 compares the respondents' reasons for keeping noncritical parts in stock to the reasons for not keeping noncritical parts in stock.

During the interviews with the respondents it became evident that the maintenance department wanted all parts in stock, whereas the supply chain and finance departments indicated that this is an area where optimisation could take place. The types of non-critical maintenance inventories indicated by the respondents during the follow-up interviews mostly included parts that could be obtained on short notice, including: consumables; steel; gas; certain motors; bearings; drill bits; hand tools; lubricants; and so on.

A lack of integration was emphasised by the conflicting objectives of the different departments. The maintenance engineering department has a key performance indicator that is linked to the operating equipment efficiency (OEE) of the equipment, as well as production output that is also linked to a strategic organisational objective. This is in contrast to the financial performance objectives of inventory turnover, low obsolescence and low investment in working capital.

The survey results indicated that the majority of the respondents $(88 \%)$ were aware of the risk of stockouts, as they regarded the classification of inventory items in terms of business risk as a necessity (Figure 5).

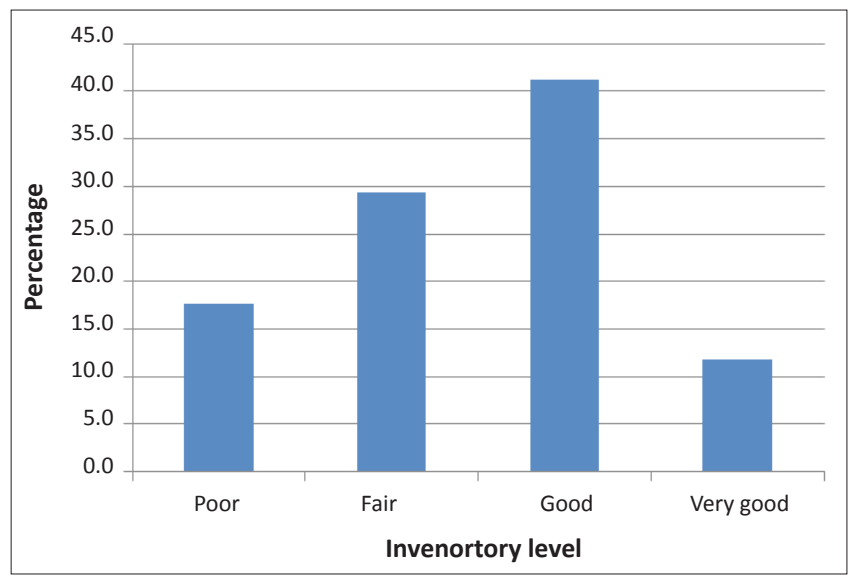

MRP, material requirements planning

FIGURE 3: Rating of inventory levels.

BOX 1: Reasons supporting inventory level ratings.

Reasons

- Critical spares are in stock - some room for improvement on smaller noncritical items.

Engineering has the idea that stores have to always have stock of everything.

- Generally spares are available when needed.

- Not too many write-offs.

- Not too many write-offs.

- Stock fluctuates, but there is not a shortage of stock.

- We never run out of spares.

- Enough stock level to service the clients as and when needed.

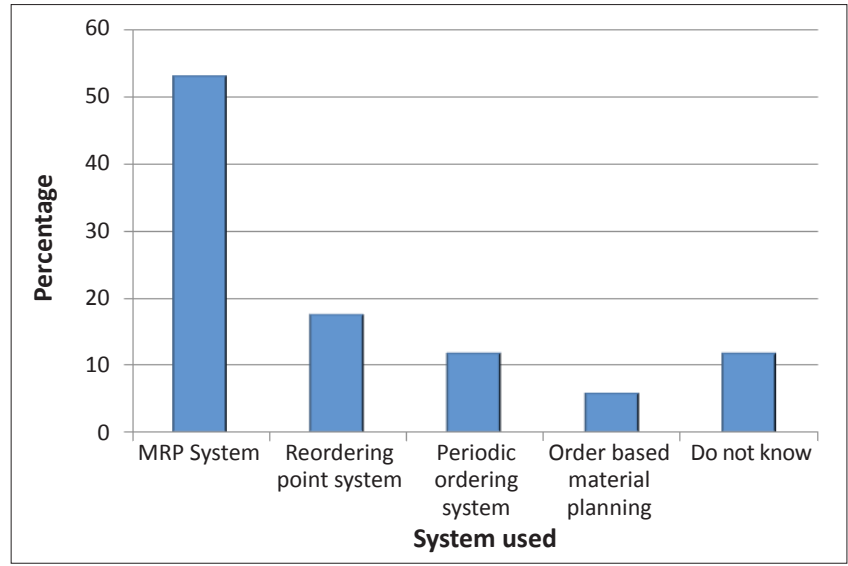

MRP, material requirement planning

FIGURE 4: Material planning system used by the cement manufacturer.

TABLE 3: Stock keeping of non-critical parts.

Reasons for keeping non-critical parts

Supplier inability to supply on time.

Reasons for not keeping non-critical parts Implement agreements with suppliers to supply on JIT basis.

Long lead times negatively impact Parts could be sourced on the same day.

Higher costs associated with unplanned

orders.

JIT, just-in-time 


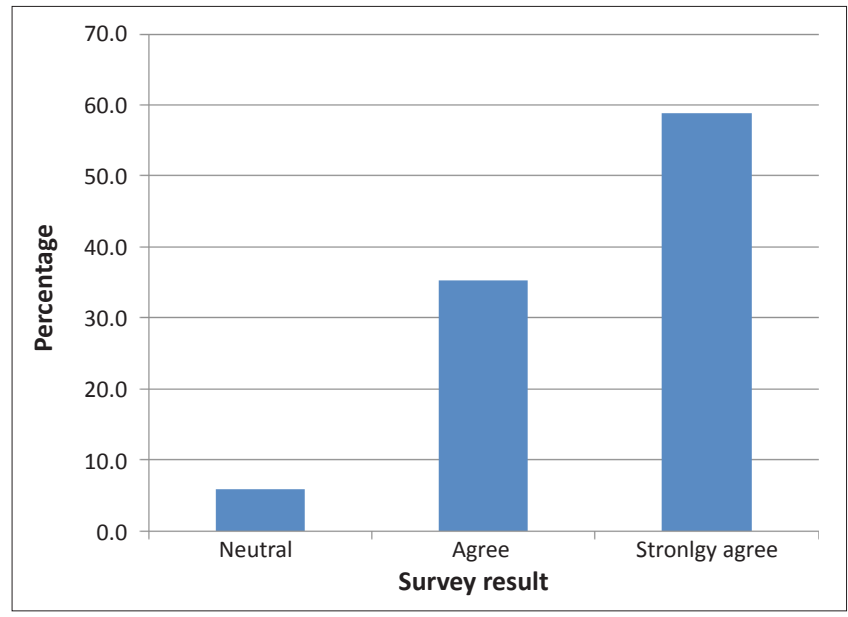

FIGURE 5: Should items be classified in terms of risk?

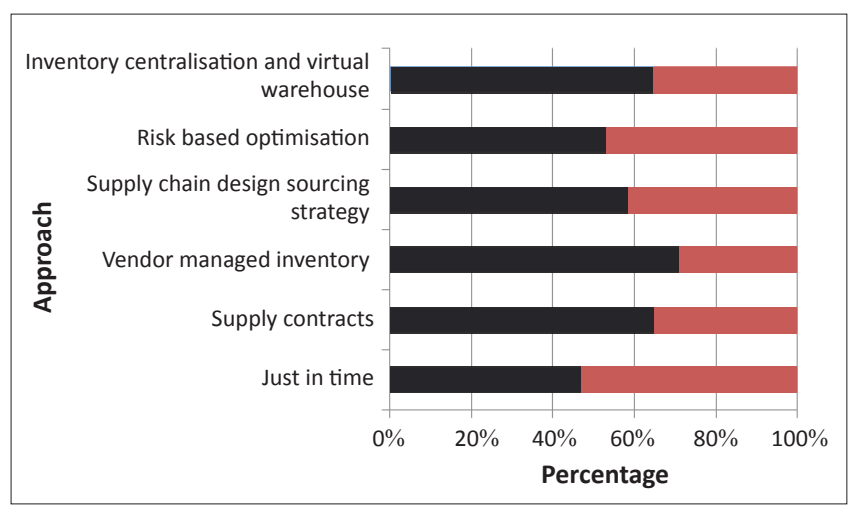

FIGURE 6: Inventory management approaches used by cement manufacturer.

The reasons provided by the respondents for classifying inventory items according to business risk indicated that they have an understanding of the impact of maintenance inventory on OEEs and the opportunity such a classification provides for optimising maintenance inventory levels.

The respondents were unsure about which of the following maintenance inventory management approaches were used by the cement manufacturer: sourcing strategy, justin-time (JIT), supply contracts, VMI, centralised or virtual warehousing or risk-based optimisation (Figure 6).

The respondents indicated that all of these six approaches were part of the inventory management approach used by the cement manufacturer. However, just-in-time (JIT), risk based optimisation and virtual warehousing were not part of inventory management at the cement manufacturer.

\section{Conclusion}

Inventory and inventory management is associated with risk (Bowersox et al. 2002) and this risk is increased in the case of maintenance inventories. Maintenance inventory includes spares and components that support the manufacturing process and it has a direct impact on the operating efficiency of the manufacturing plant. This research focused on a cement manufacturer with five geographically dispersed cement plants in Southern Africa with significant maintenance parts and component requirements, which increase operational and financial risk.

Optimal maintenance inventory management at the cement manufacturer is crucial to the financial success of the company as a result of the following factors:

- High capital cost of a number of the parts and components.

- Long lead times associated with certain parts and components.

- Impact of maintenance inventory on the operating equipment efficiency (OEE).

It was found that the focus (operationally and strategically) on OEEs resulted in a fragmented and uncoordinated approach to maintenance inventory management. This led to the slow movement of inventory items, which resulted in relatively high obsolescence figures. The lack of a proper maintenance inventory management approach of the cement manufacturer could be attributed to the following factors:

- Senior management did not understand the materials and order planning methods used by the company and its impact on inventory levels.

- There was little integration between the different departments (finance, maintenance engineering and supply chain), resulting in contrasting views on maintenance inventory levels.

- There was no measure of inventory carrying cost, resulting in a general view that inventory levels are relatively low.

- Although maintenance inventory items were classified as critical and non-critical according to risk, the classification was not taken into account in the stocking strategy, therefore the focus on operating equipment efficiencies (OEEs) resulted in the stocking of non-critical inventory items.

- Senior management was not aware of the different methods of inventory management utilised by the manufacturer.

The characteristics (planned versus scheduled maintenance, critical versus non-critical, long versus short lead time, local versus global sourcing) of the various parts and components necessitate the use of alternative approaches to the management of these inventory items.

The cement manufacturer considered certain parts to be critical for the continuation of the production process, while other parts were considered to be non-critical. This distinction between critical and non-critical maintenance spares, based on relevant criteria, could be extended by using the approach to obtain the risk profiles of the spare parts or groups of parts, as proposed by Bharadwaj et al. (2011). The risk profiles of the inventory items will allow the cement manufacturer to trade off the financial benefit against an acceptable risk level.

Although the implication of a stockout situation for a spare is difficult to quantify, it needs to be based on loss of production that will have a knock-on effect on the loss of orders and a potential loss of reputation. An alternative approach is to use a qualitative assessment of these consequences 
(Bharadwaj et al. 2011). However, such an approach requires that inventory carrying cost be utilised as a key performance indicator to highlight the overall cost of carrying inventory, especially in the light of the high level of obsolescence provision. Risk classification of maintenance inventories (or groups of inventories) would allow the cement manufacturer to successfully implement other relevant inventory management approaches such as JIT.

In addition, all the employees (senior management included) involved with inventory and inventory management should be educated in terms of the inventory management methods and approaches to be implemented and the financial impact of high inventory levels on the financial status of the company. A higher level of awareness by the employees could potentially also lead to higher levels of integration between the different departments.

\section{Acknowledgements Competing interests}

The author declares that he has no financial or personal relationship(s) that may have inappropriately influenced him in writing this article.

\section{Authors' contributions}

This article originates from the masters dissertation of M.E.'s (University of Johannesburg) based on the management of a cement manufacturer's maintenance inventory of which S.C. (University of Johannesburg) was the supervisor.

\section{References}

Baluch, N., Sobry Abdullah, C. \& Mohtar, S., 2013, 'Evaluating Effective Spare-parts Inventory Management for Equipment Reliability in Manufacturing Industries', European Journal of Business and Management 5(6), 69-75.

Berling, P., 2005, On Determination of Inventory Cost Parameters, Ph.D Thesis, Lund University, Sweden.

Bharadwaj, U.R., Silberschmidt, V. \& Wintle, J.B., 2011, 'Risk based optimisation of spares inventory management', Advances in Production Engineering and Management 63, 173-184.

Bošnjaković, M., 2010, 'Multicriteria inventory model for spare parts', Tehnički vjesnik 17(4), 499-504.

Bowersox, D.J., Closs, D.J. \& Cooper, M.B., 2002, Supply Chain-Logistics Management, Mcgraw-Hill, New York.

Cavalieri, S., Macchi, M., Garetti, M. \& Pinto, R., 2008, 'A decision making framework for managing maintenance spare parts', Production Planning and Control 19(4), 379-396. http://dx.doi.org/10.1080/09537280802034471

Chen, I.J. \& Paulra, J.A., 2004, 'Towards a theory of supply chain management: The constructs and measurements', Journal of Operations Management 22, 119-150. $\mathrm{http}: / / \mathrm{dx}$.doi.org/10.1016/j.jom.2003.12.007

Gourdin, K.N., 2001, Global logistics management: A competitive advantage for the new millennium, Oxford: Blackwell Publishers Ltd, USA

Hugo, W.M.J., Badenhorst-Weiss, J.A. \& Van Rooyen, D.C., 2002, Purchasing and Materials Management 4th edn., Van Schaik, Pretoria. PMCid:PMC2373727

Karrlson, J., Morichetto, E. \& Schwerin, A., 2007, 'How is the carrying charge determined and what connections can be identified with material planning methods?', Industrial and financial management dissertation, Spring semester, 2007.

Lambert, D.M., Stock, J.R. \& Elram, L., 2008, Fundamentals of logistics, International edn., McGraw Hill, Singapore.

Landers, T.L., Cole, M.H., Walker, B. \& Kirk, R.W., 2000, 'The virtual warehousing concept', Transportation Research Part E 36, 115-25. http://dx.doi.org/10.1016/ S1366-5545(99)00024-1

Langley, C.J., Coyle, J.J., Gibson, B.J., Novack, R.A. \& Bardi, E.J., 2009, Managing Supply Chains: A Logistics Approach, 8th edn., South-Western, Canada.

Liu, X., Cetinkaya, S., 2005, 'Designing supply contracts in supplier vs. buyer driven channels: The impact of leadership, contract flexibility and information asymmetry', IIE Transactions (2009) 41, 687-701. http://dx.doi. org/10.1080/07408170902789019

Monczka, R.M., Trent, R.J., Handfield, R.B., 2005, Purchasing and supply chain management, 3rd edn., South Western, Tenessee.

Schmitt, A., Snyder, L. \& Shen, Z-J.M., 2008, Centralization versus decentralization: Risk pooling, risk diversification and supply uncertainty in a one-warehouse multiple-retailer system, working paper, P.C. Rossin College of Engineering and Applied Sciences, Lehigh University, Bethlehem, PA. 